\title{
Between the crowd and the band: Performance experience, creative practice, and wellbeing for professional touring musicians
}

\author{
Andrew Geeves · Samuel Jones · Jane W. Davidson · John Sutton
}

\begin{abstract}
In some musical genres, professional performers play live shows many times a week. Arduous touring schedules bring encounters with wildly diverse audiences across many different performance ecologies. We investigate the kinds of creativity involved in such repeated live performance, kinds of creativity that are quite unlike songwriting and recording, and examine the central factors that influence musicians' wellbeing over the course of a tour. The perspective of the professional musician has been underrepresented in research on relations between music and wellbeing, with little attention given to the experience of touring. In this case study, we investigate influences on positive and negative performance experiences for the four professional musicians of Australian pop/rock band Cloud Control. Geeves conducted intensive cognitive ethnographic fieldwork with Cloud Control members over a two-week national Australian tour for their second album, Dream Cave (2013). Adapting a Grounded Theory approach to data analysis, we found the level of wellbeing musicians reported and displayed on tour to be intimately linked to their creative performance experiences through the two emergent, overarching and interdependent themes of Performance Headspace (PH) and Connection with Audience (CA). We explore these themes in detail and provide examples to demonstrate how $\mathrm{PH}$ and CA can feed off each other in virtuous ways that positively shape musicians' wellbeing, or loop in vicious ways that negatively shape musicians' wellbeing. We argue that their creative practice, in thus re-enacting musical performance afresh in each venue's distinctive setting, emerges within unique constraints each night, and is in a sense a co-creation of the crowd and the band.
\end{abstract}

Keywords: music performance, phenomenology, professional musician, cognitive ethnography, creative practice.

\section{Wellbeing and creativity in professional musicians}

The Tivoli, a fine old theatre and music venue in Brisbane's Fortitude Valley, is packed with 700 fans for a tour-opening gig by the alternative pop/rock band Cloud Control, who are back home on the road in Australia to promote their second album, Dream Cave (2013). On this Friday night in August 2013, as local music reviewers later write, Cloud Control send this audience "daft", "into spasms", producing "a truly electric atmosphere". Crowd responses include "delight", "general awe", and "a resounding singalong" in a set "nicely balanced between old and new tracks": the new album's "woozy psychedelia sounds great" as the gig showcases "the blissed out crooning we have come to love them for" ${ }^{\prime \prime}$. Videos shot by Geeves as part of our ethnographic project confirm such powerful, varying, and pleasure-ridden interactions between band and

\footnotetext{
${ }^{1}$ Quotations are from reviews by Paul McBridge (https://paulmcbride.me/2013/08/26/live-review-cloud-control-palms-gang-of-
} youths-the-tivoli-brisbane-23813/) and Grace Wilson (https://tonedeaf.thebrag.com/cloud-control-3/). 
crowd over this entire gig, and show audience members actively joining in, clearly loving the songs in full-bodied engagement, raised arms swaying along with the music in mass synchrony. The four musicians' post-gig conversation backstage, recorded by Geeves and discussed in more detail below, reveals their evident pleasure in this performance experience. The band members had an initial sense that "the first few songs were quite powerful", and later felt that they were "feeding off the energy of the crowd". So, they say, "we owned it", "it went really well", it was "the best sound ever"; they felt "really good and excited about the whole show", thrilled at "the kind of level of connection and engagement" they experienced from the audience. The four musicians express and demonstrate high levels of wellbeing in and after this performance.

Unfortunately, delighted audiences and musicians with demonstrably high levels of happiness and pleasure are not inevitable in live performance, as we show below in contrasting this Brisbane gig with the band's second show of the same tour, the following night. In this paper, we investigate the components of, and influences on, professional musicians' positive and negative performance experiences. We examine links between wellbeing and creative performance by asking how musicians construct, maintain, and regulate their (individual and collective) wellbeing over the course of single live shows and the extended timescale of a full and arduous tour.

\section{Overview of methods and central concepts}

This introductory section provides an overview of the central concepts and frameworks animating our project. We briefly survey general research trends on wellbeing in music, identify key components and topics in need of further study, and characterize musical creativity within a broadly ecological approach.

For current purposes, we understand both wellbeing and creativity in broad and pluralist ways. These are not concepts deployed by the musicians themselves. To analyze wellbeing and creativity, understanding these concepts broadly in the context of professional touring musicians' experience, we introduce two overarching and interdependent themes that emerged from the analysis of our case-study data. The cognitive ethnographic methods we deploy, in conjunction with an approach to data analysis inspired by Grounded Theory (Strauss \& Corbin, 1998), catch complex features operating together in the musicians' own (individual and shared) experiences of live performance. This bottom-up approach identified the themes of Performance Headspace (PH) and Connection with Audience (CA). The musicians' concept of $\mathrm{PH}$ relates to the ways their internal psychological landscapes shape, and are shaped by, performance, while CA concerns the dynamics of the musician-audience relationship. We home in on the sophisticated yet fragile strategies musicians develop for emotion-regulation and for constructing and maintaining what they regard as an optimal (or at least adequate) $\mathrm{PH}$. We examine the dynamic, looping, iterative relations between this $\mathrm{PH}$ and musicians' experiences of $\mathrm{CA}$ at each gig and across a full tour. These experiences are set within a broader distributed ecology of performance and underlie the musicians' fluctuating levels of wellbeing. Our cognitive ethnographic methods, we suggest, afford fruitful ways to tap and make sense of these diverse and variable components of musicians' experience.

\section{Wellbeing and music performance}

Wellbeing is difficult to define. Empirical studies taking wellbeing as their focus began to be conducted in the early $20^{\text {th }}$ century (for a brief history of the empirical study of wellbeing, see Diener, Lucas \& Oishi, 2002). Historically, definitions of wellbeing have fallen within two traditions: hedonic and eudaimonic (Deci \& Ryan, 2008; Ryan, Huta, \& Deci, 2013). The hedonic 
tradition has prioritized outcomes, defining wellbeing as experiences of happiness and pleasure generated when positive emotions outweigh negative emotions (Diener, Eunkook, Lucas, \& Smith, 1999; Kahneman, Diener, \& Schwarz, 1999). The eudaimonic tradition, in contrast, has prioritized process, expanding the definition of wellbeing to encompass broader, global judgments around satisfaction, meaning and engagement in relation to life (Seligman, 2002). Contemporary researchers in the field describe the ongoing difficulties involved in reaching a consensus definition of wellbeing (Clift \& Hancox, 2010; Groarke \& Hogan, 2016; Lamont, 2012).

For the purposes of this article, we define wellbeing specifically and understand it broadly. Specifically, wellbeing is defined as "a person's cognitive and affective evaluations of his or her life [that] include emotional reactions to events as well as cognitive judgments of satisfaction and fulfilment" (Diener, et al., 2002, p. 63). This definition of wellbeing synthesizes the definitional strengths of the hedonic and eudaimonic traditions, with equal importance accorded to both the outcome and process components of wellbeing. To implement or operationalize this definition, we understand wellbeing to involve a balanced combination of physical, mental, emotional, and social health. Such a pluralist and contextual approach to wellbeing (Mitchell \& Alexandrova, 2020; Alexandrova, 2017, 2012; Wren-Lewis \& Alexandrova forthcoming) is apt for application to the complex real-world setting of a working band's daily life. While akin to DeNora's social ecology (DeNora, 2013), this approach more firmly integrates cognitive processes and strategies as well as affective and environmental factors in addressing professional musicians' experiences of performance, creativity and wellbeing.

In the extensive body of research on relations between wellbeing and music, the primary foci have been music's direct effects on physiology (Kreutz, Murcia, \& Bongard 2012), and music listening (Davidson \& Krause 2018; Västfjäll, Juslin, \& Hartig 2012). Listening to music often operates in service of the self-regulation of affect to increase the frequency and intensity of positive affect, or buffer against negative affect (Laukka, 2007). Joel Krueger and colleagues develop a rich account of music as affective scaffolding, whereby music listening can afford access to novel or otherwise-inaccessible emotional experiences (Krueger, 2014, 2019). Interacting with music as a worldly, material resource within complex distributed ecologies is a central case of a broader human tendency to actively delegate the task of regulating certain features of our emotions to technological and environmental resources (Colombetti \& Krueger, 2015), actively integrating music into our emotional lives at a range of timescales (Krueger \& Szanto, 2016).

Krueger and others in these research traditions do, in principle, extend these ideas to musical performance, as well as to music listening. But fewer studies directly address wellbeing and music making. Singing together in community choirs has been found to promote wellbeing on a range of dimensions (Lee, Davidson, \& Krause, 2016). While the scope and mechanisms of these effects are not well understood (Clift \& Hancox, 2010; Gick, 2011), the establishment and consolidation of social relationships in choral singing appears to play a central role (Livesey, Morrison, Clift, \& Camic, 2012). Music students have also been studied in relation to anxiety and health (Araújo et al, 2017; Osborne, Greene, \& Immel, 2014). It has proved challenging to examine wellbeing in professional musicians (MacDonald, 2013; Davidson \& Krause, 2018), but some research suggests compromised levels of wellbeing related to stress, pain, and the intense demands of professional music making (Kenny \& Ackermann, 2016; Ascenso, Williamon, \& Perkins, 2017). Again, there are open questions concerning the significance of shared experiences and social connections of various kinds in maintaining the wellbeing of professional musicians. In a study of emotion and engagement in strong music performance experiences, for example, Lamont found few "entirely solitary experiences", such that strong experiences "were more typically shared with others (generating social meaning)" (2012, p. 588). Emotion regulation is 
strongly influenced by communication in a musical relationship (Swaine, 2014). So, just as professional musicians' relationship with their instrument is one candidate index for wellbeing (Simoens \& Tervaniemi, 2013), social relations at different timescales among musical peer groups, and between musicians and their audiences, may influence the ways in which they experience emotions around performance, with consequent effects on their wellbeing. One prior study examined variability in professional musicians' experiences of forging "connection" with an audience, in relation to pre- and post-performance routines, and the differing ways professional musicians assess and evaluate attentiveness and attunement to an audience (Geeves, Mcllwain, \& Sutton, 2016).

In this body of work relevant to wellbeing among professional musicians, the bulk of research has focussed on classical or jazz genres; and, typically, either on isolated moments of strong experience, or on larger-scale concerns about careers or health. To date there has been less scientific attention to wellbeing among pop or rock musicians, despite evident fascination with this topic in music journalism and the broader culture. Due no doubt to the practical challenges of access and immersive on-site research, very little research has addressed the daily grind and the ups and downs of touring and performing as a professional band. The current project aims to make an initial contribution on these fronts.

In certain respects, our contribution to wellbeing research is intended to be modest. Within our immersive case study, we do not argue that the performance- and audience-related factors singled out in our data exhaust the nature and components of musicians' wellbeing. Of course, as for professionals across domains, other events and concerns influence the musicians' (individual and group) wellbeing. The musicians' personal lives, for example, are not the topic of our study (though of course events in their personal lives, as well as the musicians' ways of coping with them, do in turn contribute to their headspace and wellbeing, and thus influence performances). We are not suggesting that musicians' overall wellbeing depends only on the looping connection- and audience-related $\mathrm{PH}$ on which our analysis below focuses.

That said, we believe that our immersive cognitive ethnographic method, explained in detail in the Method section below, can effectively tap the heterogeneous array of ecological factors grounding wellbeing and creativity in performance. It allows us to identify and explore in rich detail musicians' emotion regulation strategies, experiences of pleasure, conflict, or frustration, and their shifting forms of engagement with each other and their audiences.

\section{Creativity in live performance on tour}

In our case study, we treat a pop/rock band as an exemplar of a small group (for distinctive accounts of the strengths of case study research as the systematic production of exemplars for the social sciences see Flyvberg, 2016, 2011; Fine, 2012). As such, appropriate frameworks for understanding the processes and dynamics of its ongoing creative operation include studies in collaborative cognition, joint action, and social ontology (Sawyer, 2006; Larson, 2010; Preston, 2012; Tollefsen, Dale, \& Paxton, 2013; Walton et al, 2018; Pearlman, MacKay, \& Sutton, 2018). Professional musicians working in this kind of band context have honed, extended, and celebrated their collaborative embodied skill over a range of timescales. They are engaged, firstly, in expert joint actions at a technical and creative level, in terms of their unique forms of skill development, songwriting, and performance. Down to the microscales of finding the best recording in the studio, keeping time on stage, and adapting flexibly to unexpected disruptions, they have come to be able skilfully to align their actions and reactions both technically and aesthetically, and (at least when all is going well) with the appearance of effortless ease. Further, as a band with a history, a growing and increasingly international following, and a range of 
ambitions and hopes, they are also engaged in explicit, intentional, longer-term, goal-driven projects or endeavors, such as returning to Australia to promote their sophomore album after two years living and recording in London (compare Williamson \& Sutton, 2014 on the integration of interpersonal alignment in joint action with temporally-extended forms of deliberate collaboration).

A band is composed of unique individuals with distinctive skills, histories, capacities, and psychological profiles. Music brings this heterogeneity into the spotlight perhaps more clearly than for other cases of highly interactive teamwork (compare Sutton \& Tribble, 2014): lead guitarist, bass player, drummer, and keyboard player bring very different capacities to their shared projects. The band members nonetheless have a very specific shared history, as well as complex social and interactive roles and practices, at every level from the transactive division of organisational labor in administrative and logistical decision-making to the flow of banter and in-group chatter that might fill nervous moments before a big gig.

But creative processes in the context of touring musical performance differ substantially from creativity in songwriting or recording. Likewise, the creative practice of a pop/rock band touring to support a recent-release album may have little in common with that of musicians in other genres. For example, while (as we show below) the band members flexibly adapted aspects of their performance-such as repertoire, set-list, and style - to fit the venue, audience, and context, improvisation within the performance of specific songs was less important than it is in some live jazz contexts. In these respects, excellent recent research on distributed creativity in music (Clarke \& Doffman, 2017; Bishop 2018; van der Schyff et al, 2018; Wheeler, 2018; Schiavio, Moran, van der Schyff, Biasutti, \& Parncutt, 2020), within the broadly distributed or ecological 4E approach (Newen, de Bruin, \& Gallagher, 2018), has not yet sufficiently addressed live performance. In our conclusion below, we build on the fieldwork data to consider creativity in music performance more specifically. We suggest a novel account of creativity in live performance on tour in light of the notion of a "cognitive ecology", which "points to the web of mutual dependence among the elements of an ecosystem" (Hutchins 2010, p. 706) within which the experiences, emotional states, and cognitive processes of individual musicians and the band as a whole are embedded.

As experienced live performers with both longstanding and recent heavy touring schedules, the musicians are well aware that the success of each gig rests on a diverse array of factors. Some factors, such as the nature of the venues and the quality of the acoustics, are outside their control, or at least more challenging to influence at short notice. Other key factors involve their individual and shared experience, on emotional, interpersonal, technical, and aesthetic dimensions (as we discuss in detail below). The performers know that creative and powerful performances are scaffolded in complex social, institutional, technological, material environments, and are thus vulnerable to disruption in many ways. As we will demonstrate, these professional musicians develop rich, reflective individual and shared routines and strategies to help regulate their emotions, find and protect their optimal performance "headspace", set any technical or practical concerns aside for the duration of the gig, and engage freely with audiences in the moment. These are distinctive performative dimensions of creative practice. They are anchored in embodied, affective, and interpersonal skills that the musicians have developed and honed-individually and together-over their careers and their shared history of performance. In many respects they are independent of the collaborative technical and aesthetic forms of creativity operative in their songwriting and recording practice. When on tour, the technical aspects of music performance are not, ideally, at the forefront of the musicians' minds. Though they care deeply about the quality and reception of their songs, in their experience on stage, as we will see, the music matters 
less in the moment than broader expressive, aesthetic, and performative factors (compare Chaffin \& Imreh, 2002; Chaffin, Imreh, \& Crawford, 2005). While the musicians do not want to overthink the challenges of effective live performance, they want to be able to think on their feet.

The current study is motivated by a wish to observe closely the dynamic components of professional touring musicians' wellbeing over time in the challenging circumstances of a series of live performances. The opportunity to embed a researcher in the band's close circle afforded us a rare chance to trace and assess the heterogeneous and changing factors which constitute and shape the performers' experience as individuals and in the context of their rich shared history as a successful band. As in ethnographic work on theatre actors, we discuss strategies the performers have developed to gauge an audience, and to monitor the flow of audience reactions over the course of a single gig (Filmer, 2008, p. 160). In particular, we follow up on suggestions, sketched above in our review of relevant literature on wellbeing and music performance, that perceived "connection" with the audience plays a significant and variable role in sculpting what the musicians repeatedly called their headspace over the course of each gig and the tour as a whole.

\section{Participants}

\section{Method}

Our research participants were the four musicians (3 male, 1 female; age range 27-30) who comprised Australian band Cloud Control: Al Wright (lead guitar, lead vocals), Heidi Lenffer (keyboard, vocals), Jeremy Kelshaw (bass guitar, backing vocals) and Ulrich Lenffer (drums, backing vocals). Macquarie University Ethics Committee approved this research project, and all participants consented to taking part and being fully identified in this research. We use the terms performers, participants, and musicians interchangeably in this article to refer to Cloud Control members. Our study focuses solely on the experience of the music performer. Although Cloud Control members sometimes mentioned audience interaction in their accounts of performance experience, audience members were not approached for consent to take part in this study and are not treated here as participants in this research.

Cloud Control members and Geeves knew each other from growing up in neighboring suburbs in the Blue Mountains area, one hour west of Sydney, Australia. Heidi and Ulrich were raised in the same family, sharing a sibling relationship. Jeremy and Al had previously participated in research conducted by Geeves. With the exception of $\mathrm{Al}$, who started learning guitar in late adolescence, participants each had over 15 years' experience playing their primary instrument. The opportunity for Geeves to conduct fieldwork research with Cloud Control on a national tour led to the inception of this research. When this research was conducted, Cloud Control's four members had accumulated almost a decade of professional experience and successes performing together.

A sketch of Cloud Control's history provides further context. Forming in 2004-2005 and winning the Sydney University Band Competition in 2006, Cloud Control released their first recording, a self-titled EP, in 2008. Cloud Control's radio airplay and live performance opportunities steadily increased over the next couple of years, consolidating the band's presence in the Sydney music scene. With their 2010 debut album, Bliss Release, Cloud Control experienced a surge in popularity and Australian media interest and their reach expanded to a national audience. Bliss Release reached \#20 on the Australian Music Charts and saw Cloud Control win two Jägermeister Independent Music Awards (Best Independent Album, Breakthrough Independent Artist), two Sydney Music, Arts \& Culture (SMAC) Awards (Best Live Musical Act, Record of the Year), and the 2010 Australian Music Prize. Additionally, the band were nominated 
for two Australian Recording Industry Association Music Awards (ARIAs; Best Rock Album and Best Breakthrough Artist) and the Triple J 2010 J Award, produced two national Australian tours and played as the support act for high-profile international bands Supergrass and Foo Fighters on their Australian tours.

In 2011, following the success of Bliss Release, Cloud Control signed to record and management labels in the UK and relocated to London for the launch of Bliss Release to the UK market. Over the next couple of years, the band interspersed working on a second album, which would come to be titled Dream Cave, with extensive touring throughout the UK and Europe to continue to promote Bliss Release. Dream Cave was released in August 2013. The accompanying national promotional tour for this album was the focus of our research.

\section{Design}

We used a case study research design inspired by Grounded Theory (Glaser \& Strauss, 1967; Strauss \& Corbin, 1998). Grounded Theory emphasizes bottom-up theory-building derived from strict adherence to data, and is useful when close examination of experience is sought and there is a paucity of existing theory on a topic (Henwood \& Pidgeon, 2003). Geeves conducted exploratory, ethnographic, short-term, intensive, qualitative fieldwork with Cloud Control. We did not design our research to provide an exhaustive account of factors that influence and overdetermine performer wellbeing, but aimed to stick closely to participants' experience over the course of our research, following participants' leads and tracking the particular factors that they identified as contributing to their wellbeing in these moments, at these times, and on this tour. Like Høffding's semi-structured, qualitative interviews with members of the Danish String Quartet (Høffding, 2019; Høffding \& Martiny, 2016; Schiavio \& Høffding, 2015), phenomenology occupied a central position in this research project. We designed an immersive study with the view to gather data that would be rich in its level of detail and idiosyncrasy. Tracking the musicians so closely afforded the opportunity to catch their unique (individual and shared) emotion-regulation strategies and their reflections on how daily creative practice might continue to flourish as conditions and challenges varied over the course of the tour. The band members were well aware that theirs were not the only ways of maintaining creative and affective equilibrium. As Al put it on one occasion, "This is the Cloud Control method, because there are so many different ways". Our ethnographic approach provides more direct, experience-near access than other methods might to the kind of shared expertise to which $\mathrm{Al}$ was referring here, and to the musicians' striking meta-awareness of their methods of self-regulation and what we might call "band-regulation".

In line with Fassinger's (2005) suggestion of applying to qualitative research "the traditional validity, reliability, generalisability and objectivity/neutrality standards applied to quantitative studies" (p.163), we incorporated self-reflective and self-reflexive practices into our research process with the view of boosting the trustworthiness of our data collection and analysis. For example, in line with best practice in Grounded Theory (Strauss \& Corbin, 1998), Geeves explicated his conceptual framework prior to data collection, did not generate any a priori hypotheses, and maintained regular reflective diary entries for the duration of his fieldwork (see Browne \& Sullivan, 1999). In so doing, Geeves sought to occupy a participant-observer position in which he remained mindful of the way in which his presence and intersubjectivity might affect observed phenomena. In this way, our study added to previous qualitative phenomenological research (e.g., Høffding, 2019) and an awareness and acknowledgment of the ways in which the contents of observed phenomena can be changed, influenced and co-constructed by the presence of an observer. 


\section{Procedure}

\section{Data Collection}

Data collection occurred from 23 ${ }^{\text {rd }}$ August 2013 to $12^{\text {th }}$ September 2013, as Geeves accompanied Cloud Control on their Australian Dream Cave tour through Queensland, New South Wales, the Australian Capital Territory and Victoria for a total of 12 performances (see Table 1). During this period, Geeves audio-recorded 23 interviews with participants. Interviews were conducted at opportune times in the late morning or early afternoon when participants were not involved in other work on tour. Open-ended questioning was used to explore participants' tour and performance experiences. All four participants were interviewed as a group on eight occasions, different combinations of three or two participants were the subjects of eight interviews, and solo research participants featured in seven interviews. These interviews totaled eight hours of data. Geeves video-recorded all 12 performances, as well as backstage moments before and after performance in which musicians were talking about performance both amongst themselves and to Geeves. Interviews were recorded on a Sony IC digital audio recorder (ICD-UX80) recorder to which a Sony Electret Condenser Microphone (ECM-DS70P) was connected to maximize sound quality for later transcription. Video footage was captured with a Sony Handycam 80GB DCRSR68 handheld video recorder. All interactions with participants, including interviews and backstage conversations, were structured by holding in mind the two interrelated processes of asking questions and making comparisons that underlie Grounded Theory.

\section{Data Analysis}

In line with Grounded Theory, we transcribed all interviews and then analyzed interview data through a rigorous cross-coding process. All authors worked together to identify, synthesize and link emergent thematic categories in the data that were of interest to performer wellbeing. We then presented these to Jeremy and incorporated his feedback. Specifically, Jeremy pointed us towards highlighting more explicitly the bidirectional shaping of the performer-audience relationship, and emphasising the ways in which each musician's performance experiences are co-constructed by the perceived experiences of audience members and other onstage musicians. In presenting our findings, we begin with an example of a performance that involved high levels of performer wellbeing, explore in more detail themes that emerged from our data as shaping performer wellbeing, and end with an example of a performance that involved lower levels of performer wellbeing. 
Table 1

Performance Schedule for Cloud Control's Dream Cave Australian Tour

\begin{tabular}{lll}
\hline Date & Location & Venue \\
\hline $23 / 8 / 13$ & Brisbane & The Tivoli \\
\hline $24 / 8 / 13$ & Caloundra & Kings Beach Tavern \\
\hline $25 / 8 / 13$ & Byron Bay & Beach Road Hotel \\
\hline $28 / 8 / 13$ & Canberra & ANU Bar \\
\hline $30 / 8 / 13^{*}$ & Adelaide & The Governor Hindmarsh Hotel \\
\hline $31 / 8 / 13^{*}$ & Perth & The Capital \\
\hline $3 / 9 / 13$ & Melbourne & University of Melbourne \\
\hline $3 / 9 / 13$ & Mornington Peninsula & Private residence \\
\hline $4 / 9 / 13$ & Ballarat & Karnova Lounge \\
\hline $5 / 9 / 13$ & Bendigo & Star Bar \\
\hline $7 / 9 / 13$ & Melbourne & The Forum \\
\hline $8 / 9 / 13^{*}$ & Tasmania & Republic Bar \\
\hline $10 / 9 / 13$ & Sydney & Carriageworks (FBi 10th Birthday) \\
\hline $11 / 9 / 13$ & Wollongong & Wollongong Uni Bar \\
\hline $12 / 9 / 13$ & Newcastle & Bar on the Hill \\
\hline
\end{tabular}

* = Geeves did not accompany Cloud Control for these portions of the tour.

\section{Results}

Wellbeing in Action: When Things Go Well - The Tivoli, Brisbane

As mentioned earlier, participants had favorable experiences of the first tour performance at The Tivoli in Brisbane. Participants' accounts of this performance were uncomplicated and unambiguous in their positive hedonic tone. Put simply, performers considered this a good performance. Everyone felt pleased. All had fun. Unsurprisingly, participants expressed and demonstrated high levels of wellbeing in relation to this performance. The musicians described experiencing pleasure within themselves during performance, which formed a strong foundation for pleasurable experiences with the audience during performance. This then further increased the pleasure performers experienced within themselves, which in turn increased the pleasurable experiences they had with others, and this loop continued to build over the performance. Participants reported feeling energized, enthused, accomplished, and in good spirits after the performance.

Participants unanimously reported the positive ways in which they felt The Tivoli performance shaped their experience. For example, they shared their performance experiences of enjoyment, satisfaction and absorption:

J: I think it went really well. I was really happy with it.

U: Same!

H: We owned it!

A: I felt pretty good, pretty calm. I wasn't really thinking about it. 
J: I felt relief... this is working...then you just enjoy it, have a great time, chill with the crowd.

Participants identified a range of factors that contributed to the favorable qualities of their experience. Both Heidi and Ulrich remarked on how the quality of the band's sound scaffolded their performance confidence:

U: I had the best sound ever.

H: It's all about what kind of sound you get on stage. If the mix is out, it can make an otherwise great gig a really poor experience. It's important that the mix gets nailed.

For Heidi, the confidence and enjoyment she experienced was enhanced by feeling able to join with her fellow bandmates in what she experienced as their confidence and enthusiasm during performance:

Al really brought it from the start and that made me feel really good and excited about the whole show. I'm affected by how these guys are enjoying it. We're feeding off each other. If people aren't having a good time, it makes it harder for you to rise above it.

Jeremy described how freedom from expectations and pressures from external agents contributed to the enjoyment in his performance experience:

There were no industry douchebags, no "You have to go and meet these people or hang out with this guy". We just got to do what we wanted to do.

All musicians also described feeling deeply connected, in a positive way, to and with the Tivoli audience during performance. Ulrich summarized his experience of gauging a high level of interest and investment from the audience:

The first few songs were quite powerful. We experienced the level [of connection] and engagement we normally experience from a crowd for our big singles, but these were singles that haven't been out for very long. It was a really good response that set the tone for us.

In her description of the energy that she experienced receiving back from the audience, Heidi captured the sense of feeling connected to the audience that participants commonly reported across all of their performance experiences at The Tivoli:

I was feeding off the energy of the crowd, especially when they were doing these ones [raises hands] in "Dojo rising"... it was a nice revelation that this song was connected.

Musicians' descriptions of their performance experiences at The Tivoli demonstrate how performance can impact musicians' wellbeing in a positive way. Musicians' individual and shared positive experience were apparent both in participants' words and in Geeves' observations, revealing personal and collective wellbeing. This positive experience reflects and was grounded both in the musicians' own satisfaction and engagement in performance - as individual musicians and as a band with shared goals and values - and in their sense of a creative and active, mutually-reinforcing positive relationship with the gig's audience. However, the above discussion draws on only one performance of the 13 that were the focus of our 
ethnographic work. The next part of our analysis is motivated by wanting to more precisely render the aspects of performance experience contributing to musicians' wellbeing. We now present a more detailed analysis of the relationship between performance and musicians' wellbeing over the full course of the Cloud Control tour fieldwork.

\section{Exploring Wellbeing: Performance Headspace and Connection with Audience}

The musicians demonstrated high levels of self-reflective awareness in their accounts of their tour performance experiences. Their expertise was by no means only technical and aesthetic: they also deployed sophisticated insights and subtle strategies in promoting and enhancing positive experiences both for themselves and for their audiences in the changing and often challenging tour contexts. We found that what emerged in the space between the musicians and audience in performance occupied a central role in participants' performance experience and had a strong influence on their wellbeing. According to Al:

The crowd is just as important as the band. It's all about the crowd, but then it's all about the band. It's all about what is between the two.

Two overarching, interdependent themes emerged from the data analysis as characterising what lies between the musician and the audience: Performance Headspace (PH) and Connection with Audience (CA). PH and CA are in a cyclic relationship, and influence performer wellbeing both separately and together. These two factors lie at the heart of live performance practice in this context and this genre of creative musical activity. $\mathrm{PH}$ and $\mathrm{CA}$ are so central in performance experience that musicians pay more attention to establishing a favorable $\mathrm{PH}$ and strong $\mathrm{CA}$ than to the need for masterful execution of musical technique, or even to the music itself. "Playing an instrument is only a small part of playing live", said Al, "It's not really about the music...the most important thing is connection".

Participants described how they experienced $\mathrm{PH}$ and $\mathrm{CA}$ as sharing a looping, interdependent relationship. Participants recognized $\mathrm{PH}$ as preceding $\mathrm{CA}$, believing it was not possible for the audience to enjoy themselves during a performance without musicians also enjoying themselves. "I think when we have a good time, audiences have a good time", said Jeremy, "And that's the ultimate aim, is for the audience to have a good time". Yet CA also fed back into PH. "I feel like it's a different experience when you're onstage and playing songs to a crowd that is not giving back to the energy", said Ulrich, "They're just taking your energy". "I feed off the energy of the crowd a lot", stated $\mathrm{Al}$, "I don't like feeling like we're an afterthought. You don't want to play to people who are in a line to get food...It's not fun for me to play to people as a sideline". We found that the closer participants came to achieving a favorable $\mathrm{PH}$, the greater likelihood there was of being able to establish a strong CA which, in turn, increased the likelihood of participants being able to sustain a favorable PH. As demonstrated in The Tivoli performance example, we found this type of mutually reinforcing "virtuous" looping between $\mathrm{PH}$ and CA to have a positive impact on performer wellbeing. Yet we also found that $\mathrm{PH}$ and CA could loop in a less virtuous way, with a less favorable PH decreasing the likelihood of establishing a strong CA, which in turn resulted in an even less favorable PH. As we show below in a second detailed performance example, we found this type of "vicious" looping to have a negative impact on performer wellbeing.

As we begin to explore $\mathrm{PH}$ and $\mathrm{CA}$, it is worth noting that while participants spoke directly from their own subjective experience, they could speak only about their perceptions of others' experience. It is possible that an audience member's account of her experience of a Cloud Control 
tour performance could differ from participants' perceptions of that audience member's experience of the same performance. As stated earlier, an understanding of audience experience is beyond the scope of this research. While our video data include some footage of audience behavior across the tour gigs, we focused exclusively here on performers' expectations and beliefs about audience responses and did not triangulate these with any independent measures of audience experience.

\section{Performance Headspace (PH)}

Performance Headspace is best understood as participants' mindset about performance. It is an in vivo concept that first arose in Al, Jeremy and Ulrich's discussion of their internal psychological landscapes in relation to music performance. Participants recognized that headspace differed between performances. Better performances were associated with more favorable headspaces. For example, Al described his ideal performance as involving "the same kind of mindset as a really great party where you' re just doing what you want to do and hanging out", before adding "It's pretty much the same headspace". For Ulrich, "How you're feeling on the day is how you perform", and if a musician is experiencing trepidation or "something is going on, you're unable to get into that headspace as much". Participants also placed importance on a capacity to inhabit a certain level of agency, choice, proactivity and reflexivity in relation to PH. "I feel like we're learning to be proactive in our headspaces", said Jeremy, "I feel like we're getting to a point where we've decided what matters so we can go and try to achieve that mentally."

Our analysis of participants' descriptions of performance experience yielded a small set of key and sometimes overlapping features of a favorable $\mathrm{PH}$. The more favorable musicians' $\mathrm{PH}$ for a performance, the higher their associated levels of wellbeing. Participants were striving for a PH in which they could enjoy performing their music. "I think our best performances are when we enjoy it", said Jeremy. The musicians also aimed for feelings of satisfaction, accomplishment and validation in their experience of performance. "Playing a good gig is one of the most satisfying things in my life", said Al, "When you're just bringing everyone together, it's fucking awesome". Participants viewed absorption in performance as another desirable feature of PH. With a tongue-in-cheek reference to Eminem, Al captured the immersive experience he pursued in performance, while acknowledging its elusive nature:

I just want to be like Eminem and lose myself in the moment. Every night. That's all I want to do... not thinking about anything, just playing the songs and enjoying... If I can do that, that's great. It doesn't always happen.

Similarly, Heidi and Ulrich described desirable performance experiences characterized by the dissolution of top-down tracking of experience. "You stop approaching it as watching yourself onstage and thinking about how you look and what you're doing" said Ulrich. Heidi likened this to a flow state in which there are "No feelings of awkwardness [and] you're allowed to feel. Awkwardness takes you out of the moment. It makes you self-conscious. It breaks up a flow" (see Geeves, McIlwain, Sutton, \& Christensen, 2014; and Høffding, 2019 for more on absorption during performance). We found participants also aimed for a $\mathrm{PH}$ that allowed flexibility and adaptation in the face of ever-changing situational demands. "It's a specific, esoteric thing that's different every time", Jeremy said, "You can't have any preconceptions about what to do, unless what you do is adapt, cause that's all you can do" (italics added). Heidi provided an example of this adaptation when she described actively lowering her expectations during a performance. "I 
was talking myself into a better state of acceptance", she explained, "I thought it would be inappropriate to be jumping up and down in front of people who were just looking at a fish tank rather than engaging".

$\mathrm{PH}$ never occurs in a vacuum. While we found the musicians striving for a particular ideal quality of $\mathrm{PH}$, they did not do so from a neutral starting point. $\mathrm{PH}$ is always situated in a particular personal and collective history and context. It would be naïve to consider musicians as blank slates in relation to PH. A variety of other factors contribute to performer wellbeing such as residual moods, and individual and collective reactions to where musicians have just been and where they need or want to go - and all have ongoing influence on musicians' $\mathrm{PH}$. Thinking of musical creativity and performance within a cognitive ecological framework also underlines the fragility of these core features of a favorable PH. As none of these are guaranteed to occur or to be sustained during a performance, performers' wellbeing is vulnerable to shifting influences over the course of performance.

Participants reported two paradoxical-sounding strategies they followed to try to instil a favorable PH. The first strategy is best summarized as trying not to try. "Don't focus on having a good show", said Al. "If you try and do what you want to do, maybe you don't end up doing it", stated Jeremy in agreement, "It's almost impossible". Notions of authenticity, honesty and lack of pretension abounded in participants' descriptions of this strategy. "It's all about chilling out, doing what you're doing and being yourself", explained Al, "That's what people want to see. It's like a performance but it's a natural thing". The second strategy identified by participants involved the notion of letting go. "Letting go is really just remembering that there is a lot of stuff that doesn't matter", said Al, "The only thing that ever holds me back from having a good gig is my own brain".

On the surface, the strategies participants reported using in the pursuit of a favorable $\mathrm{PH}$ might seem at odds with the levels of engagement and investment that music performance requires of musicians. During performance, it is almost as if participants did not want to be perceived by audience members as performing. Maintaining the fourth wall was important. Perhaps the musicians did not want to be seen by the audience as trying too hard, fearing this might have adverse ramifications for the musician-audience relationship. This is a fascinating double strategy of dialling up displays of authenticity and of a down-to-earth onstage presence, while also consciously trying to loosen egoic attachment to performance. These kinds of tensions or apparent paradoxes are familiar across a range of performance and skill domains, perhaps further entrenched through the expectations or cultural conventions intrinsic to certain genres of music performance. They may perhaps reveal how the musicians mitigate and manage the pressure of expectations by acting as if the stakes of performance are lower than they actually are. Whatever the more specific reasons behind their use, these strategies served to enhance and protect participants' wellbeing in relation to music performance.

In addition to describing $\mathrm{PH}$ features and strategies, participants identified two further factors that shaped $\mathrm{PH}$ and influenced their wellbeing: confidence and pressure. In terms of confidence, Jeremy noted: "It's about having confidence that permeates everything you do", "It is not about the one performance, it is an across the board thing". Participants could not establish confidence in performance without a baseline feeling of ease about the technical mastery and sound of their songs (see Chaffin et al., 2005, for rich description of how "chunking" the lowerlevel technical elements of performance allows performers to concentrate on their higher-level expressive and aesthetic goals and processes). Participants also described how the pressure they felt from themselves or others about performance could affect their PH: "As soon as anyone starts putting pressure on musicians it's very hard", said $\mathrm{Al}$, "I can't stress enough how bad it is when 
someone tells you to play well. Or to go nuts. It's the worst thing someone can do". The precise mechanisms by which such pressure might disrupt creative practice in such performance situations are not clear from consideration of our data alone.

\section{Connection with Audience (CA)}

We found CA to be the second overarching theme in participants' descriptions of performance experience. We see CA as the quality of connection a musician experiences with an audience. Participants viewed $\mathrm{CA}$ as analogous to establishing and maintaining conversation. Al viewed $\mathrm{CA}$ as "Just like any human interaction with another person. You have to treat the other person with respect, take them seriously and be yourself", and felt strong CA was akin to the "good feeling of empathising with someone else and having a good conversation". "It's silly to think of the crowd as a crowd", said Al, explaining his bespoke frame for establishing CA: "You have to be talking to them as a person in a small group. You are connecting, hopefully, with each person individually". Al also explained how CA can shape performer wellbeing in a markedly positive or negative way:

The thing about being on stage is that it can easily flip the other way, where you feel like you're four people against a larger number of people. If a gig goes badly, it's when you start to feel like you're not in the right place. But if you feel like everyone is there with you and you're supporting each other to make something together, that's cool. That's what it should always be like... All I want to do is connect with people and really just feel like I'm having a good time.

Here, Al spoke to the ongoing knife's-edge on which the CA dynamic rests during performance. At any time, CA could go either way. When it comes to wellbeing, CA is high risk, high gain.

We found emotional attunement, communication, and matching to be the key ingredients musicians reported working with when trying to establish CA. Participants described how it was crucial to try to attune to the quality and quantity of emotion that they felt was present in an audience. For $\mathrm{Al}$, the main thing on stage was to "Be really with the people who are in the room; really take them on to the stage with you and realize that they came out to see you play". Similar to Filmer's (2008, p. 160) actors who stand in the wings and monitor the flow of performance and reactions of an audience, participants described how a part of them would be constantly observing and monitoring feedback data received from the audience during performance including the amount of dancing, talking, eye contact, silence and singing along occurring in the crowd. This process helped participants to attune to the audience and modify their performance accordingly.

In this way, the musicians aimed to communicate emotion during performance in a way that was as inclusive as possible for as many audience members as possible. "If you're communicating a feeling, you just have to be really careful that you're bringing everyone with you and you're not being a jerk", explained Al.

The band made on-the-fly adjustments to the setlist over the course of the tour, and this enabled them to maximize the likelihood of CA they read as a "party crowd", "all-ages crowd" and "crowd of fans". "You want to meet the audience", said Jeremy, "If they're super crazy, you ride that energy wave. If they're super chilled, then you chill out a bit more. What we all want is a matching". Matching is all about balancing needs. It involves the ongoing process during performance of a musician gauging emotion experience in an audience, weighing this with an 
awareness of what they as a musician are experiencing emotionally and then trying to find a point of intersection.

Ideally, matching does not have to involve compromise. In Jeremy's words, "A good gig is matching what the audience wants with what we want as well". Practically, compromise is often required. Yet participants also identified parameters outside of which they were unwilling to compromise. Cloud Control did not offer the same performance to all audiences. Audiences had to demonstrate a desire for interaction that would then be deemed high-enough to earn them the best parts of musicians' performance. "It's the extra stuff on top, the stuff that makes you enjoy the show more and allows the audience to interact with you", said Heidi, "If they're not wanting to interact, then you don't give them that stuff". As we will see in the next example, the musicians held these boundaries in relation to matching to protect their wellbeing from being too buffeted by audiences who they felt were uninterested in connection.

\section{Wellbeing in Action II - When Things Go Wrong: Kings Beach Hotel, Caloundra}

Good feeling was in short supply amongst participants as they discussed the second performance of the tour at Kings Beach Tavern, Caloundra, a coastal, working-class town at the southernmost end of the Sunshine Coast Region in South East Queensland. Participant experiences ranged from "ok" for Al to "fine" for Jeremy and Ulrich to a "real struggle" for Heidi. In contrast to the virtuous cycle of $\mathrm{PH}$ and $\mathrm{CA}$ that governed the performance at The Tivoli, a vicious cycle was established at Kings Beach Hotel. PH was less than ideal, CA was limited and challenging to establish and maintain, and this then continued to weigh down PH. Feelings of flatness, disappointment, shock, anger, relief that the performance was over and a sense of wanting to leave the performance in the past dominated participants' accounts of this performance. Unsurprisingly, participants expressed and demonstrated lower levels of wellbeing in relation to this performance.

In contrast to participants' experience of $\mathrm{PH}$ at The Tivoli, participants felt their confidence levels were adversely affected by experiencing a lack of trust in the competence of the in-house sound technician at Kings Beach Tavern. "The in-house sound guy was super flaky. At least he turned up", sighed Jeremy, with resignation. Participants described how their PH was also negatively impacted by the lack of a private backstage area in which they were able to prepare prior to performance. As a result of this, participants, especially Heidi and Ulrich, felt acutely affected by the lack of control they were able to exercise over separation from the audience before and after performance.

Participants also found it difficult to establish and maintain CA during performance. Al described finding it challenging to attune emotionally to an audience that he experienced as signalling a hyper-masculine flavor of aggression: "I saw a lot of guys with drinks doing guy dancing and bumping into people and being annoying. Caloundra felt a bit more aggressive". If CA at Caloundra was a conversation, participants experienced the interaction as forced and their interlocutors to be disinterested in the particularities of the band and possessive of an energy that was at best disorganized, intoxicated and excessive, and, at worst, tumultuous, disrespectful and hostile. Participants discussed experiencing a sense of feeling like interchangeable background party noise in Caloundra and contrasted this with feeling appreciated by fans at The Tivoli:

J: People come because they want something to do as much as wanting to see you. In Brisbane, you only get people who really want to see you because they've got more options, but in a small town like this, it's different. 

A: I think they have a lot more patience to come with you in Brisbane. In Caloundra, the crowd was partying but... they might not be our biggest fans. They want cheap thrills, man. They want to go and see a band and have a good time and hang out. And you can tell.
$J$ : They knew the singles off the radio, and just wanted to party. And it's not going to see Cloud Control, it's going to the...
A: Pub
J: It's just the thing in town to do.
U: They're willing to give you five minutes of their short attention span and unless you fulfil exactly what they want in those five minutes then they're just gone, off to buy a beer.
J: They don't want to connect with you. They just want your songs to be there so they can connect with each other... So you end up just playing your party hits.

Participants' feelings of disempowerment and despondency were palpable in their discussion of the Kings Beach Tavern performance experience. The musicians felt marginalized and overlooked by the audience, treated as if their function was that of a jukebox, providing loud background music against which a disengaged crowd could enjoy vigorously bumping into each other.

The limitations participants experienced in relation to establishing CA had ramifications for the extent to which they felt it was possible to match the audience and maintain CA during this performance. In contrast to the expansive range of matching that became possible in The Tivoli performance, participants felt constricted by their perception of the audience's emotion experience:

H: It means you can't be as indulgent. A quiet song like "Just For Now" demands more of an audience, demands them to behave more respectfully than perhaps that audience wanted to be.

A: It demands people pay attention to a really dark stage for four minutes. And that's why, in the right crowd, that song can be a highlight. But then with the wrong crowd, it can be the worst song in the set. It's really bad singing a song like that and just hearing people talk all the way through. Last night, they were very talky and very dancey. These often go hand in hand. People just want to dance with their friends 'cause they're having a really good time and it's like "Yeah cool, alright". Not all songs are appropriate.

J: So you have to meet them in the middle. You can't just demand that they pay attention because it's probably going to suck.

H: 'Cause they're going to have a better time and we're going to have a better time as well. A: They're only going to pay attention to certain things as well. You have to shout at them and hit them with a big stick, but with other crowds you can really talk to them and engage with them on a more personal level.

As evident in the discussion above, participants felt that the low level of CA at Kings Beach Tavern left them with no choice but to deliver a less personal, less engaged performance, confined to operating within narrower parameters than The Tivoli performance.

Over the course of the tour, if Cloud Control felt an audience was invested enough in a performance, they would "indulge" in a surprise rendition of a cover of an excerpt from the Butthole Surfers' song "Pepper" during the breakdown section of their song "Gold Canary". This surprise consistently heightened apparent positive emotion during performance for both audiences and performers. Our observations suggest that audiences loved being "treated" in this 
way, and the presence or absence of this example of "extra stuff on top" that participants could include in performance came to be an effective shorthand indicator of strength of CA during performance. The Kings Beach Tavern audience were not privy to this experience. An unfavorable $\mathrm{PH}$ and an audience that felt largely disinterested in connection could have disastrous impact on wellbeing. Consequently, self-protection and minimising the negative impact on wellbeing of such a performance became central in their performance experience. "I spent most of the time just going to my happy place, pretending the show wasn't happening, but it was", said Heidi, "What it became was an endurance".

\section{Conclusion}

In this study, we explored the relationship between musicians' creative performance experience and wellbeing. We did so using a cognitive ethnographic methodology, conducting intensive fieldwork with the musicians in Cloud Control over the course of 13 performances on their 2013 Dream Cave Australian tour. We found the level of wellbeing musicians reported and displayed on tour to be intimately linked to their creative performance experiences through the two overarching and interdependent themes of $\mathrm{PH}$ and CA. As demonstrated in The Tivoli performance example, $\mathrm{PH}$ and CA could feed off each other in virtuous ways that positively shaped musicians' wellbeing. Alternatively, as shown in the Kings Beach Tavern performance, $\mathrm{PH}$ and CA could also loop in vicious ways that then negatively shaped musicians' wellbeing.

The picture we have painted in this study of wellbeing and the way in which it is shaped by creative performance experience is far from exhaustive. The parameters of our case study design necessitated zooming in on what wellbeing looks like over a relatively short amount of time for a small number of participants situated in very specific relationship with each other within delimited social, cultural and historical contexts. The thickness of data yielded by this research is simultaneously its greatest strength and limitation. Our immersive research provides rich insight into how creative performance experience shaped wellbeing for Cloud Control members on this tour. By sticking closely to musicians, by having the opportunity to move slowly alongside them in their experiences of performance and wellbeing on the tour, our study has taken the time to locate and put under the microscope everyday nuances of their touring life that may, ordinarily, remain overlooked or undetected.

We noted above that musical creativity is typically theorized in the contexts of songwriting, recording, or improvisatory performance. The physically and emotionally taxing context of work as a professional touring band demands different forms of creative practice. This is where the ecological approach to distributed creative cognition comes into its own. In performing their songs each night, warding off the challenges and dangers of monotony, unresponsive audiences, or imperfect sound, the band was obviously not bringing something entirely new into being: their successful repertoire, including the increasingly popular songs on their new album, anchored their enduring appeal to large crowds. Yet something fresh did emerge every night, as the musicians worked with the unique constraints of each venue, each audience, each soundworld. Here, as the band labored to earn their keep in criss-crossing this huge country, creativity in performance always arose afresh. This emergent form of creativity was co-created by, or between, the crowd and the band, in each unique musical ecology.

So just as the musicians' experience was influenced by a collaborative, porous process, so too was their technical and aesthetic creative practice intrinsically distributed in performance, across an array of social and material resources. Musical creativity in a working band is hybrid, distributed across mutually supporting interactions, across the changing environments which shape their $\mathrm{PH}$, and across the fragile yet potentially powerful senses of energy and connection 
they can, on occasion, experience emerging between the crowd and the band. Any attempt to understand musical creativity on tour that did not adopt a distributed ecological approach, but restricted its focus to the thoughts, feelings, and aesthetic judgements of the four individual musicians alone, would miss the crucial ways that the balances shift over the heterogeneous elements of their performance ecologies. It would miss the changing spaces, sound systems, audience moods, and external pressures. Our study offers a glimpse of how musicians manage the vulnerability of their (individual and collective) wellbeing in relation to performance experience, and of what they bring to the space between the band and the audience in attempting to bolster or insulate their wellbeing. As a small group of very different individuals with specialized skills and unique characteristics, Cloud Control have developed their own "method", as $\mathrm{Al}$ put it, for maintaining equilibrium and satisfaction through the testing creative processes involved in an arduous tour. This method includes a unique mix of more implicit and embodied ways of coping with challenges, and a sophisticated array of more explicit, self-aware strategies for regulating emotion and wellbeing over time.

Yet what would the strategies for regulating wellbeing in relation to creative performance experience look like for bands with a shorter history than Cloud Control? What about bands that had been together for a longer time? How many strategies from "The Cloud Control method" might overlap with those used by a death metal band? How might they compare to strategies used by a jazz quartet or by a classical orchestra? What might PH and CA look like in the performance experience of a DJ or a punk rock band? What similarities and differences might exist in the way in which these factors shaped their wellbeing?

There are many potential avenues for future research in this area. Future work might explore in more depth underlying factors that may feed into PH and CA and also influence musician wellbeing (e.g., physical performance environment, previous performance experiences, perceived characteristics of and investment from audience). It could also build a model of what lies between the band and the audience that was at a level of abstraction broad enough to be able to be applied to understanding the relationship between wellbeing and performance experience for musicians from a variety of genres and who differed in their levels of expertise. Future ethnographic work could also focus on the audience rather than the performer. How might the wellbeing of an audience member be shaped by her experience of live music performance? A model of what lies between the crowd and the band (audience perspective) could then be integrated with a model of what lies between the band and the crowd (performer perspective) to fully map what arises in this space in relation to creative performance experience and its ties to wellbeing.

\section{Acknowledgements}

We are hugely grateful to the members of Cloud Control for participating in our study by welcoming a researcher into their inner circle during an arduous and professionally significant tour. Doris Mcllwain was a key collaborator and supporter at the time the fieldwork was undertaken, and is much missed. We also thank our colleagues in the Cognitive Ecologies research group at Macquarie University, especially Kath Bicknell and Greg Downey, for specific feedback and suggestions. This research was funded by ARC (Australian Research Council) Discovery Project grants DP130100756 to Doris Mcllwain and John Sutton, DP140102679 to Jane Davidson, and DP180100107 to John Sutton.

\section{Conflict of interest statement}

The authors report no conflicts of interest.

\section{Authors}


Andrew Geeves

Macquarie University

Samuel Jones

Macquarie University

Jane W. Davidson

University of Melbourne

John Sutton

Macquarie University

john.sutton@mq.edu.au

\section{Publishing Timeline}

Received 2 September 2020

Accepted 26 November 2020

Published 17 December 2020

\section{References}

Alexandrova, A. (2012). Values and the science of well-being: A recipe for mixing. In H. Kincaid (Ed.), The Oxford handbook of philosophy of social science (pp. 625-645). Oxford University Press. https://doi.org/10.1093/oxfordhb/9780195392753.013.0026

Alexandrova, A. (2017). A philosophy for the science of well-being. Oxford University Press. https://doi.org/10.1093/oso/9780199300518.001.0001

Araújo, L. S., Wasley, D., Perkins, R., Atkins, L., Redding, E., Ginsborg, J., \& Williamon, A. (2017). Fit to perform: An investigation of Higher Education music students' perceptions, attitudes, and behaviors toward health. Frontiers in Psychology, 8, 1558.

https://doi.org/10.3389/fpsyg.2017.01558

Ascenso, S., Williamon, A., \& Perkins, R. (2017). Understanding the wellbeing of professional musicians through the lens of Positive Psychology. Psychology of Music, 45(1), 65-81. https://doi.org/10.1177/0305735616646864

Bishop, L. (2018). Collaborative musical creativity: How ensembles coordinate spontaneity. Frontiers in Psychology, 9, 1285.

Browne, J., \& Sullivan, G. (1999). Analysing in-depth interview data using grounded theory. In V. Minichello (Ed.), Handbook for research methods in health sciences. Addison-Wesley.

Chaffin, R., \& Imreh, G. (2002). Practicing perfection: Piano performance as expert memory. Psychological Science, 13(4), 342-349. https://doi.org/10.1111/j.0956-7976.2002.00462.x

Chaffin, R., Imreh, G., \& Crawford, M. (2005). Practicing perfection: Memory and piano performance. Lawrence Erlbaum Associates Publishers.

Clarke, E. F., \& Doffman, M. (Eds.). (2017). Distributed creativity: Collaboration and improvisation in contemporary music. Oxford University Press. https://doi.org/10.1093/oso/9780199355914.001.0001

Clift, S., \& Hancox, G. (2010). The significance of choral singing for sustaining psychological wellbeing: Findings from a survey of choristers in England, Australia and Germany. Music Performance Research, 3, 79-96.

Cloud Control. (2010). Bliss Release [Album]. Ivy League Records.

Cloud Control. (2013). Dream Cave [Album]. Ivy League Records.

Colombetti, G., \& Krueger, J. (2015). Scaffoldings of the affective mind. Philosophical Psychology, 28(8), 1157-1176.00 https://doi.org/10.1080/09515089.2014.976334

Davidson, J. W., \& Krause, A. E. (2018). Social and applied psychological explorations of music, health and well-being. In N. Sunderland, N. Lewandowski, D. Bendrups, \& B-L. Bartleet (Eds.), Music, 
health and wellbeing: Exploring music for health equity and social justice (pp. 33-63). Palgrave Macmillan. https://doi.org/10.1057/978-1-349-95284-7 3

Deci, E. L., \& Ryan, R. M. (2008). Hedonia, eudaimonia, and well-being: An introduction. Journal of Happiness Studies, 9(1), 1-11. https://doi.org/10.1007/s10902-006-9018-1

DeNora, T. (2013). Music asylums: Wellbeing through music in everyday life. Ashgate. https://doi.org/10.1111/1467-9566.12198

Diener, E., Eunkook, M.S., Lucas, R. E., \& Smith, H. L. (1999). Subjective well-being: Three decades of progress. Psychological Bulletin, 125(2), 276-302. https://doi.org/10.1037/0033-2909.125.2.276

Diener, E., Lucas, R. E., \& Oishi, S. (2002). Subjective well-being: The science of happiness and life satisfaction. In C. R. Snyder \& S.J. Lopez (Eds.), Handbook of positive psychology (pp. 63-73). Oxford University Press.

Fassinger, R. E. (2005). Paradigms, praxis, problems, and promise: Grounded theory in counseling psychology research. Journal of Counseling Psychology, 52(2), 156-166. https://doi.org/10.1037/0022$\underline{0167.52 .2 .156}$

Filmer, A. (2008). Minding the gap: The performer in the wings. New Theatre Quarterly, 24(2), 158-169. https://doi.org/10.1017/S0266464X08000134

Fine, G. A. (2012). Tiny publics: A theory of group action and culture. Russell Sage Foundation. https://www.jstor.org/stable/10.7758/9781610447744

Flyvberg, B. (2011). Case study. In N.K. Denzin \& Y.S. Lincoln (Eds.), The Sage handbook of qualitative research (pp. 301-316). Sage Publications Ltd.

Flyvberg, B. (2016). Five misunderstandings about case-study research. Qualitative Inquiry, 12(2), 219-245. https://doi.org/10.1177/1077800405284363

Geeves, A., Mcllwain, D. J., Sutton, J., \& Christensen, W. (2014). To think or not to think: The apparent paradox of expert skill in music performance. Educational Philosophy and Theory, 46(6), 674-691. https://doi.org/10.1080/00131857.2013.779214

Geeves, A. M., McIlwain, D. J., \& Sutton, J. (2016). Seeing yellow: ‘Connection' and routine in professional musicians' experience of music performance. Psychology of Music, 44(2), 183-201. https://doi.org/10.1177/0305735614560841

Gick, M. L. (2011). Singing, health and well-being: A health psychologist's review. Psychomusicology: Music, Mind and Brain, 21(1-2), 176. https://doi.org/10.1037/h0094011

Glaser, B. G., \& Strauss, A. L. (1967). The discovery of grounded theory: Strategies for qualitative research. Aldine Publishing Company.

Groarke, J. M., \& Hogan, M. J. (2016). Enhancing wellbeing: An emerging model of the adaptive functions of music listening. Psychology of Music, 44(4), 769-791.

https://doi.org/10.1177/0305735615591844

Henwood, K., \& Pidgeon, N. (2003). Grounded theory in psychological research. In P. M. Camic, J. E. Rhodes, \& L. Yardley (Eds.), Qualitative research in psychology: Expanding perspectives in methodology and design (pp. 131-155). American Psychological Association. https://doi.org/10.1037/10595-000

Høffding, S. (2019). A phenomenology of musical absorption. Palgrave Macmillan.

Høffding, S., \& Martiny, K. (2016). Framing a phenomenological interview: What, why and how. Phenomenology and the Cognitive Sciences, 15(4), 539-564. https://doi.org/10.1007/s11097-015-9433$\underline{z}$

Hutchins, E. (2010). Cognitive ecology. Topics in Cognitive Science, 2(4), 705-715. https://doi.org/10.1111/j.1756-8765.2010.01089.x

Kenny, D., \& Ackermann, B. (2016). Optimising physical and psychological health in performing musicians. In S. Hallam, I. Cross, M. Thaut (Eds.), Oxford handbook of music psychology (pp. 633-647). Oxford University Press. https://doi.org/10.1093/oxfordhb/9780198722946.013.38

Kahneman, D., Diener, E. \& Schwarz, N. (Eds.). (1999). Well-being: The foundations of hedonic psychology. Russell Sage Foundation. https://www.jstor.org/stable/10.7758/9781610443258

Kreutz, G., Murcia, C. Q., \& Bongard, S. (2012). Psychoneuroendocrine research on music and health: An overview. In R. A. R. MacDonald, G. Kreutz, \& L. A. Mitchell (Eds.), Music, health and wellbeing (pp. 457-476). Oxford University Press. https://doi.org/10.1093/acprof:oso/9780199586974.003.0030 
Krueger, J. (2014). Affordances and the musically extended mind. Frontiers in Psychology, 4, 1003. https://doi.org/10.3389/fpsyg.2013.01003

Krueger, J. (2019). Music as affective scaffolding. In D. Clarke, R. Herbert, \& E. Clarke (Eds.), Music and consciousness II (pp. 55-70). Oxford University Press. https://doi.org/10.1093/oso/9780198804352.003.0004

Krueger, J., \& Szanto, T. (2016). Extended emotions. Philosophy Compass, 11(12), 863-878. https://doi.org/10.1111/phc3.12390

Lamont, A. (2012). Emotion, engagement and meaning in strong experiences of music performance. Psychology of Music, 40(5), 574-594. https://doi.org/10.1177/0305735612448510

Larson, J. R., Jr. (2010). In search of synergy in small group performance. Psychology Press.

Laukka, P. (2007). Uses of music and psychological well-being among the elderly. Journal of Happiness Studies, 8(2), 215-241. https://doi.org/10.1007/s10902-006-9024-3

Lee, J., Davidson, J. W., \& Krause, A. E. (2016). Older people's motivations for participating in community singing in Australia. International Journal of Community Music, 9(2), 191-206. https://doi.org/10.1386/ijcm.9.2.191 1

Livesey, L., Morrison, I., Clift, S., \& Camic, P. (2012). Benefits of choral singing for social and mental wellbeing: Qualitative findings from a cross-national survey of choir members. Journal of Public Mental Health, 11(1), 10-26. https://doi.org/10.1108/17465721211207275

Mitchell, P., \& Alexandrova, A. (2020). Well-being and pluralism. Journal of Happiness Studies. Advance online publication. https://doi.org/10.1007/s10902-020-00323-8

Newen, A., De Bruin, L., \& Gallagher, S. (Eds.). (2018). The Oxford handbook of 4E cognition. Oxford University Press. https://doi.org/10.1093/oxfordhb/9780198735410.001.0001

Osborne, M. S., Greene, D. J., \& Immel, D. T. (2014). Managing performance anxiety and improving mental skills in conservatoire students through performance psychology training: A pilot study. Psychology of Well-Being, 4(1), 18. https://doi.org/10.1186/s13612-014-0018-3

Pearlman, K., MacKay, J., \& Sutton, J. (2018). Creative editing: Svilova and Vertov's distributed cognition. Apparatus. Film, Media and Digital Cultures of Central and Eastern Europe, (6). http://dx.doi.org/10.17892/app.2018.0006.122

Preston, B. (2012). A philosophy of material culture: Action, function, and mind. Routledge.

Ryan, R. M., Huta, V., \& Deci, E. L. (2013). Living well: A self-determination theory perspective on eudaimonia. In A. Delle Fave (Ed), The exploration of happiness (pp. 117-139). Springer. https://doi.org/10.1007/978-94-007-5702-8 7

Sawyer, R. K. (2006). Group creativity: Musical performance and collaboration. Psychology of Music, 34(2), 148-165. https://doi.org/10.1177/0305735606061850

Schiavio, A., \& Høffding, S. (2015). Playing together without communicating? A pre-reflective and enactive account of joint musical performance. Musicae Scientiae, 19(4), 366-388. https://doi.org/10.1177/1029864915593333

Schiavio, A., Moran, N., van der Schyff, D., Biasutti, M., \& Parncutt, R. (2020). Processes and experiences of creative cognition in seven Western classical composers. Musicae Scientiae. https://doi.org/10.1177/1029864920943931

Simoens, V. L., \& Tervaniemi, M. (2013). Musician-instrument relationship as a candidate index for professional well-being in musicians. Psychology of Aesthetics, Creativity, and the Arts, 7(2), 171. https://doi.org/10.1037/a0030164

Strauss, A. L., \& Corbin, J. (1998). Basics of qualitative research: Techniques and procedures for developing grounded theory (2nd ed.). Sage Publications Ltd.

Sutton, J., \& Tribble, E.B. (2014) The creation of space: Narrative strategies, group agency, and skill in Lloyd Jones's The book of fame. In C. Danta and H. Groth (Eds.), Mindful aesthetics: Literature and the sciences of mind (pp. 141-160). Bloomsbury Continuum.

Swaine, J. S. (2014). Musical communication, emotion regulation and the capacity for attention control: A theoretical model. Psychology of Music, 42(6), 856-863. https://doi.org/10.1177/0305735614545197

Tollefsen, D. P., Dale, R., \& Paxton, A. (2013). Alignment, transactive memory, and collective cognitive systems. Review of Philosophy and Psychology, 4(1), 49-64. 
https://doi.org/10.1007/s13164-012-0126-z

van der Schyff, D., Schiavio, A., Walton, A., Velardo, V., \& Chemero, A. (2018). Musical creativity and the embodied mind: Exploring the possibilities of $4 \mathrm{E}$ cognition and dynamical systems theory. Music $\mathcal{E}$ Science 1. https://doi.org/10.1177/2059204318792319.

Västfjäll, D., Juslin, P. N., \& Hartig, T. (2012). Music, subjective wellbeing, and health: The role of everyday emotions. In R. A. R. MacDonald, G. Kreutz, \& L. A. Mitchell (Eds.), Music, health and wellbeing (pp. 405-423). Oxford University Press.

https://doi.org/10.1093/acprof:oso/9780199586974.003.0027

Walton, A. E., Washburn, A., Langland-Hassan, P., Chemero, A., Kloos, H., \& Richardson, M. J. (2018). Creating time: Social collaboration in music improvisation. Topics in Cognitive Science, 10(1), 95-119. https://doi.org/10.1111/tops.12306

Wheeler, M. (2018). Talking about more than heads: The embodied, embedded and extended creative mind. In B. Gaut \& M. Keiran (Eds.), Creativity and philosophy (pp. 230-250). Oxford University Press. https://doi.org/10.4324/9781351199797

Williamson, K., \& Sutton, J. (2014). Embodied collaboration in small groups. In C.T. Wolfe (Ed.), Brain theory: Essays in critical neurophilosophy (pp. 107-133). Palgrave Macmillan. https://doi.org/10.1057/9780230369580 7

Wren-Lewis, S., \& Alexandrova, A. (forthcoming). Mental health without wellbeing. The Journal of Medicine and Philosophy. https://doi.org/10.17863/CAM.43878 